\title{
Risk-Informed Sustainable Development in the Rural Tropics
}

\author{
Maurizio Tiepolo ${ }^{1, *(\mathbb{D})}$, Vieri Tarchiani ${ }^{2} \mathbb{( 1 )}$ and Alessandro Pezzoli ${ }^{1}$ \\ 1 DIST-Interuniversity Department of Regional and Urban Studies and Planning, Politecnico and University \\ of Turin, 10125 Turin, Italy; alessandro.pezzoli@polito.it \\ 2 Institute of Bio Economy, National Research Council of Italy, 50019 Sesto Fiorentino, Italy; \\ vieri.tarchiani@ibe.cnr.it \\ * Correspondence: maurizio.tiepolo@polito.it; Tel.: +39-11-0907491
}

Citation: Tiepolo, M.; Tarchiani, V.; Pezzoli, A. Risk-Informed Sustainable Development in the Rural Tropics. Sustainability 2021, 13, 4179. https:/ / doi.org/10.3390/su13084179

Received: 30 March 2021

Accepted: 7 April 2021

Published: 9 April 2021

Publisher's Note: MDPI stays neutral with regard to jurisdictional claims in published maps and institutional affiliations.

\section{Overview}

In the tropics, rural areas are still the place where many people live, despite ongoing urbanization. In tropical Africa, most of the population is still rural and will be so for at least another generation [1,2]. The development of the rural tropics is not merely a contribution to the growth of individual countries. It can be a way of reducing poverty $[3,4]$ and inequalities in access to water [5], health care [6], and education [7] that the process of urbanization is unable to alleviate. However, it can also be a way to reduce greenhouse gas emissions that drive climate change if rural development is pursued in a sustainable way. This means stopping deforestation [8]. Then, reducing livestock-related emissions, which now account for $56 \%, 83 \%$, and $87 \%$ of the greenhouse gases produced in Asia, Latin America, and Africa, respectively, according to the Food and Agricultural Organization's latest estimates [9].

Efforts to achieve sustainable rural development are often thwarted by hydro-climatic disasters (droughts, flooding, heavy rains, typhoons) which local communities are little prepared to tackle. Understanding these disasters, improving preparation, and strengthening governance have become equal priorities of the Sendai Framework for Disaster Risk Reduction [10]. However, the implementation of disaster risk reduction (DRR) at local scale, to achieve the objectives of the Sendai framework, has come across innumerable obstacles. It is often the case that agricultural practices and local planning are not very risk-informed. Climatic information is absent or not accessible locally [11]. Early warning systems and climate services are habitually not constructed with and for the rural communities [12,13]. Exposure and vulnerability are frequently considered as static determinants of risk [14]. Finally, the frequency and quality of DRR mainstreaming in local development plans are low $[15,16]$ or simply unknown $[17,18]$. These deficiencies are particularly acute in the Tropics, where many Least Developed Countries are located, and where there is, however, great potential for agricultural development $[19,20]$.

This Special Issue aims to investigate ways of increasing local knowledge of risks to contribute to rural development. It also aims to ascertain the status of essential resources, such as water and soil, and identify what undermines their integrity. Finally, it seeks to identify local policies for risk reduction and adaptation. The 22 articles collected here cover case studies from 12 countries. More than half of the articles concern Africa, as the subcontinent contains most of the Earth's surface in the tropical zone. The 94 authors mobilized cover a wide range of disciplines, such as agronomy, architecture, civil engineering, climatology, earth sciences, ecology, economic policy, environmental engineering, geography, geology, geomatics, hydraulics, materials science, oceanography and atmospheric physics, remote sensing, and spatial and regional planning.

\section{A Short Review of the Contributions}

Eleven articles are devoted to the knowledge of risk. Two of them are dedicated to hazard knowledge. Vigna et al. consider the best datasets among the Climate Hazards 
Group InfraRed Precipitation with Station, the Global Precipitation Climatology Center, and the Kenyan Meteorological Dataset to observe monthly rainfall trends in the North Horr subcounty in northern Kenya between 1983 and 2014. As a result, the Kenyan Meteorological Dataset corrected with a procedure based on the Global Precipitation Climatology Center monthly dataset performs better in terms of resolution and response to local scale precipitation differences.

Baldi et al. consider the severe thunderstorms in Sinai (Egypt) and their future trend. This hazard impacts the arid region as flash floods, which can be a resource if captured by water harvesting works.

Flood exposure is analyzed by Galligari et al. in a $135 \mathrm{~km}^{2}$ of the most densely populated wetlands in Niger: The Maouri temporary creek in Guéchémé. The dynamics of the built-up area in the flood zone are observed over the last ten years. Human settlements appear to be expanding by $52 \%$ in flood prone zones. House consolidation with corrugated sheet metal roofs is stronger in that zone than outside it.

Caselle et al. present a dataset to appreciate the vulnerability of local communities to drought and other threats in the Hodh Chargui region of Mauritania. The dataset is useful for drafting local development plans for the 31 municipalities that make up this vast jurisdiction.

Tiepolo et al. present a pluvial and fluvial risk assessment in four rural settlements along the Sirba River, in western Niger. The assessment is conceived to support planning risk reduction. Set up in a participatory manner, it employs innovative techniques in the region (images captured by unmanned aerial vehicles, hydraulic modelling), integrated with local knowledge. The result is a support to informed decision-making in prioritising and implementing risk reduction policies that local assessments rarely provide.

With another article, Tiepolo et al. offer a similar assessment considering meteorological, hydrological, and agricultural drought and flood risk for 13 rural communities in the Hodh Chargui, Mauritania. A large variability of risk level emerges within a relatively limited geographical area, determined by the risk of heavy rains and agricultural drought. These results are useful to identify risk reduction actions, which are very different from those usually proposed by the literature.

Frontuto et al. propose an assessment of flood impacts in Duran district, Ecuador, that considers income distribution and risk adversity instead of standard monetary damage. This influences damage compensation and the identification of priority areas for intervention.

Risk perception is the subject of the article by Gomez Zapata et al. in the case of the Cotopaxi volcano, Ecuador. The use of modelling for exposed areas identification facilitates discussion with local communities and awareness. Furthermore, it allows us to understand where exposure perceived by communities does not coincide with that calculated with the model.

Finally, three articles deal with the early warning and forecasting of extreme events. Tarchiani et al. present a locally and community-based flood early warning system designed with, and implemented for, the riverine communities along the Sirba River in western Niger. The main result is the demonstration that an early warning system can be set up operationally, involving the beneficiary communities through observation and preparedness.

Bacci et al. analyze the meteorological services delivered by the National Directorate of Meteorology to rural communities from eight municipalities of the Dosso and Tillaberi regions to reduce drought risk in agriculture. Feedback from users demonstrate the positive perception of such services and the willingness to use them, despite the intrinsic incertitude.

Ebhuoma et al. investigate the use of climate services by three rural communities in the Niger delta (Nigeria). Authors find a local preference for using indigenous knowledge rather than climate services due to the lack of local weather stations, the precedent of wrong weather predictions, and the misuse of local communication channels. A way out could be to develop pilot projects with farmers who are willing to use climate services. 
Nine articles are dedicated to the state of water and soil, and the threats to these two key natural resources for rural development. Bonetto et al. consider the status of water resources in three districts of the Ethiopian Rift Valley. The study observes trends in fluoride presence, $\mathrm{pH}$, and electrical conductivity values in the wells. The information obtained is useful for increasing access to drinking water in this semi-arid region.

Bertone et al. consider monitoring the presence of fertilizers on waterways in tropical Australia. The use of a mobile station for real-time monitoring of water quality, especially nitrate detection, proves advantageous over traditional laboratory sampling analysis. Nitrates have fluctuations in concentration in a short time that mobile stations can detect.

Water pollution by fecal matter is the subject of the article by Bigi et al. on North-Horr subcounty in Kenya. The presence of nitrates in water sources, and measures foreseen by local government to reduce it, highlight the greater vulnerability of the northern part of the subcounty to this threat.

Baratta et al. focus on actions to ensure greater access to water in the Kayes region of Mali. In particular, the reconstruction of damaged mini-dams with the participation of beneficiary communities is described. The restored dams increase the development of micro businesses.

Lasagna et al. consider the availability of water in Gumbo, east of Juba, South Sudan. The results of the study demonstrated the peculiarity of surface and groundwater and the critical aspects to consider for water use, particularly due to the exceeding of limits suggested by the $\mathrm{WHO}$ and national regulations. This research represents a first step for the improvement of water knowledge and management, for sustainable economic development, and for social progress in this African region.

Acciarri et al. consider the best option for producing drinking water at Magoodhoo island, Maldives, whose lens freshwater was damaged by the 2004 tsunami. The result is that a reverse osmosis desalination plant, powered by a photovoltaic plant with batteries, is economically and environmentally more advantageous than using a diesel desalination plant and bottled water supply.

Figueroa et al. consider the impacts of converting forests to grassland in tropical Mexico. The focus is on the dynamics of carbon, nitrogen and phosphorous balances in soil. The study observes a carbon and nutrient loss due to land use change.

Watene et al. observe soil erosion between 1990 and 2015 in the Great Rift Valley region of Kenya. Agriculture with poor soil and water conservation measures in Lake Nakuru and Bogoria-Baringo lake watersheds drive the highest erosion rates. Conservation tillage, curbing deforestation and overgrazing are recommended.

Drextler investigates climate smart agriculture adaptation in Belize. The author finds mulching, soil nutrient enrichment, and cover practices typical of Mayan farming tradition to have positive influences. However, these practices are made unsustainable by poverty, population growth and deforestation. This calls for a renewed commitment of agriculture extension services.

Two articles deal with adaptation and risk reduction at the local scale but observed in a wider context: Nigeria and tropical Africa as a whole. Ogunpaimo et al. identifies the relationship between adaptation and food security and what characteristics of rural households and farms facilitate it. The author finds that adaptation increases food security and that it is linked to access to credit and extension services.

Finally, Tiepolo et al. investigate the state of disaster risk reduction mainstreaming in local development plans for 198 rural jurisdictions over tropical Africa. Emphasis is placed on the quality of the plans rather than their number, as is done in the monitoring of the Sendai framework for DRR. Lack of climate characterization, little DRR, and low participation characterize these plans, which remain anchored in providing basic services such as as electricity, water, sanitation, and hygiene.

In the rural tropics, local communities are exposed to climate-related hazards, as well as to an unsustainable use of land and water resources. Their role in the economy and society is too important to be obscured by urban-centric policies. Support for local risk 
reduction should be more concerned with informing rural communities, building shared responses to face threats, and the quality of policies implemented, instead of merely considering their quantity.

The guest editors would like to thank the Italian Agency for Development Cooperation (AICS) and the ANADIA 2.0 project for their support in producing this Special Issue.

\section{References}

1. Mercandalli, S.; Losch, B. (Eds.) Rural Africa in Motion. In Dynamics and Drivers of Migration South of the Sahara; FAO; CIRAD: Rome, Italy, 2017.

2. UNDESA-United Nations Department of Economic and Social Affairs. World Urbanization Prospects. The 2018 Revision; United Nations: New York, NY, USA, 2018.

3. Diao, X.; Hazell, P.; Thurlow, J. The Role of Agriculture in African Development. World Dev. 2010, 38, 1375-1383. [CrossRef]

4. Barrett, C.B.; Christiaensen, L.; Sheahan, M.; Shimeles, A. On the Structural Transformation of Rural Africa. J. Afr. Econ. 2017, 26, i11-i35. [CrossRef]

5. Agrawal, T. Educational inequality in rural and urban India. Int. J. Educ. Dev. 2014, 34, 11-19. [CrossRef]

6. Adams, E.A.; Smiley, S.L. Urban-rural water access inequalities in Malawi: Implications for monitoring the Sustainable Development Goals. Nat. Resour. Forum 2018, 42, 217-226. [CrossRef]

7. Yaya, S.; Uthman, O.A.; Okonofua, F.; Bishwajit, G. Decomposing the rural-urban gap in the factors of under-five mortality in sub-Saharan Africa? Evidence from 35 countries. BMC Public Health 2019, 19, 616. [CrossRef] [PubMed]

8. Pearson, T.R.H.; Brown, S.; Murray, L.; Sidman, G. Greenhouse gas emissions from tropical forest degradation: An underestimated source. Carbon Balance Manag. 2017, 12, 3. [CrossRef] [PubMed]

9. FAO. Greenhouse Gas Emissions from Agriculture, Forestry and Other Land Use; FAO: Rome, Italy, 2016.

10. UNISDR. Sendai Framework for Disaster Risk Reduction 2015-2030; UNISDR: Geneva, Switzerland, 2015.

11. Brasseur, G.P.; Gallardo, L. Climate services: Lessons learned and future prospects. Earth's Future 2016, 4, 79-89. [CrossRef]

12. Gautam, D.K.; Phaiju, A.G. Community Based Approach to Flood Early Warning in West Rapti River Basin of Nepal. J. Integr. Disaster Risk Manag. 2013, 3, 155-169. [CrossRef]

13. AsimZia, A.; Wagner, C.H. Mainstreaming Early Warning Systems in Development and Planning Processes: Multilevel Implementation of Sendai Framework in Indus and Sahel. Int. J. Disaster Risk Sci. 2015, 6, 189-199. [CrossRef]

14. Jurgilevich, A.; Räsänen, A.; Groundstroem, F.; Juhola, S. A systematic review of dynamics in climate risk and vulnerability assessments. Environ. Res. Lett. 2017, 12, 013002. [CrossRef]

15. Lyles, W.; Berke, P.; Smith, G. A comparison of local hazard mitigation plan quality in six states, USA. Landsc. Urban Plan. 2014, 122, 89-99. [CrossRef]

16. Horney, J.; Nguyen, M.; Salvesen, D.; Dwyer, C.; Cooper, J.; Berke, P. Assessing the Quality of Rural Hazard Mitigation Plans in the Southeastern United States. J. Plan. Educ. Res. 2016, 37, 56-65. [CrossRef]

17. UNDRR. Global Assessment Report on Disaster Risk Reduction; UNDRR: Geneva, Switzerland, 2019.

18. UNDRR. Monitoring the Implementation of Sendai Framework for Disaster Risk Reduction 2015-2030: A Snapshot of Reporting for 2018; UNDRR: Bonn, Germany, 2020.

19. Altieri, M.A.; Nicholls, C.I. The adaptation and mitigation potential of traditional agriculture in a changing climate. Clim. Chang. 2013, 140, 33-45. [CrossRef]

20. Meijer, S.S.; Catacutan, D.; Ajayi, O.C.; Sileshi, G.W.; Nieuwenhuis, M. The role of knowledge, attitudes and perceptions in the uptake of agricultural and agroforestry innovations among smallholder farmers in sub-Saharan Africa. Int. J. Agric. Sustain. 2015, 13, 40-54. [CrossRef] 